\title{
ECOLOGICAL ASSESSMENT OF THE TERRITORY, TAKING INTO ACCOUNT THE FUNCTIONAL HETEROGENEITY OF CERTAIN CATEGORIES OF LANDS
}

\author{
Glukhovskaya Marina Yuryevna, candidate of technical sciences, \\ associate professor of Ecology and Nature Management Department \\ Evstifeeva Tatyana Aleksandrovna, candidate of agricultural sciences, \\ associate professor of Ecology and Nature Management Department \\ Grivko Elena Vasilyevna, candidate of pedagogical sciences, \\ associate professor of Ecology and Nature Management Department \\ Orenburg State University (Orenburg, Russian Federation)
}

\begin{abstract}
Widespread degradation of natural ecological systems dictates the need to establish their stability limits, which are largely reflected in the change of the environmental components properties as a result of various factors, primarily anthropogenic ones. Sustainability is expressed by a coefficient defined as the ratio of the areas of the territories under the elements of a favorable and negative impact. Determination of the coefficient of ecological stability implies taking into account the ecological significance of each of the biotechnical elements of the terrain. This methodology assumes several stages of research: analysis of the structure of the land fund of the region, identification of priority categories of land, assessment of the contribution of individual biotechnical elements within the categories in maintaining environmental sustainability and stability. The research was carried out on the territory of the Orenburg Region, where the agro-industrial sector prevails, characterized by a high rate of growth of disturbed lands. The assessment was carried out for the period from 2002 to 2016. The study showed that agricultural land is a priority area, accounting for $88,5 \%$ of the total area. They are divided into arable land $(55,9 \%)$, fodder land $(43,5 \%)$, perennial plantations $(0,5 \%)$ and other lands $(0,1 \%)$. The value of the stability coefficient during the whole period of the study is on average 0,36 , which is $29,5 \%$ below the minimum norm and characterizes the territory as unstable. The maximum value of the stability index is 0,79 with an optimal value of at least 1 , which allows us to classify the research area as «less stable». The obtained values of the parameters studied make it possible to draw conclusions about going beyond the limits of the stability of the ecosystems in the Orenburg Region and violating the stability of their development. Reducing the burden on the land fund of the region under study will allow a differentiated approach, based on the system of ecological zoning.

Keywords: land fund; anthropogenic soil conversion; land fund structure; ecological significance of biotechnical elements; ecological zoning; ecosystem self-regulation; ecological sustainability; ecological stability; ecological stabilization of lands.
\end{abstract}

УДК $57.04+574.4$

DOI 10.24411/2309-4370-2019-12105

Статья поступила в редакцию 20.02.2019

\section{ЭКОМОРФНЫЙ АНАЛИЗ ФЛОРЫ ПРИГОРОДНЫХ ЛЕСОВ Г. САМАРЫ}

(C) 2019

Матвеева Татьяна Борисовна, кандидат биологических наук, доцент кафедры биологии, экологии и методики обучения

Казанцев Иван Викторович, кандидат биологических наук, доцент кафедры химии, географии и методики их преподавания, декан естественно-географического факультета

Молчатский Сергей Львович, кандидат физико-математических наук, доцент кафедры химии, географии и методики их преподавания

Самарский государственный сочиально-педагогический университет (г. Самара, Российская Федерация)

Аннотация. В ходе проведённого исследования выявлено, что лесные массивы пригородных лесов г. Самары испытывают в настоящее время значительную антропогенную нагрузку, которая связана, в первую очередь, с увеличением площади дачных участков, несанкционированной застройкой территории, вырубкой деревьев, значительной рекреационной нагрузкой. Для выделенных ассоциаций проведён экоморфный анализ флоры - все встреченные виды распределены по ценоморфам, гигроморфам и трофоморфам. На основании полученных данных было установлено преимущественное распространение элементов флоры и выявлены основные последствия антропогенной трансформации. Можно заключить, что структура травостоя пригородных лесов г. Самары изменяется по мере повышения антропогенной нагрузки. Это отражается в увеличении доли рудерантов, ксеромезофитов и мезоксерофитов, не свойственным для лесных сообществ. На основании полученных данных можно определить степень нарушенности растительного покрова под влиянием антропогенного воздействия. Выявлено, что в пригородных лесах г. Самары, несмотря на высокую привлекательность и комфортность, жизненное состояние древостоев дуба черешчатого оценивается в основном как ослабленное, что требует проведения комплекса лесохозяйственных мероприятий по оптимизации рекреационного лесопользования по улучшению состояния лесных насаждений и повышения их устойчивости в условиях антропогенной нагрузки. Данные материалы могут служить основой для последующего изучения флоры указанного района.

Ключевые слова: антропогенное воздействие; рекреационная нагрузка; пригородные леса; ассоциации; древостои; дубрава; липняк; экоморфный анализ флоры; сосудистые растения; ценоморфа; гигроморфа; трофоморфа; жизненные формы; жизненное состояние; сухостой; лесообразующая порода; Quercus robur L.; мониторинг. 
Матвеева Т.Б., Казанцев И.В., Молчатский С.Л.

\section{Введение}

Дуб черешчатый является основной породой в лесных сообществах степи и лесостепи и в Самарской области дубравы занимают около 210 тыс. га., что составляет 37,9\% покрытых лесом земель. Из них $83 \%$ приходится на свежие, $10,7 \%$ - на влажные, $5,2 \%$ - занимают сухие, $0,9 \%$ - сырые, $0,2 \%$ - мокрые. Формируются, в основном, на чернозёмовидных и суглинистых почвах. Естественные дубняки не отличаются высокой производительностью и представлены III, IV классом бонитета. Древостои высших бонитетов составляют всего лишь $3 \%$ площади лесов области [1, с. 151]. Встречаются дубовые леса во всех лесхозах области, но наиболее распространены в Сергиевском, Кинельском, Красноярском, Рождественском, а также, повсеместно, на территории Самарской Луки [2, с. 34-38]. В южных районах небольшие участки произрастают по склонам лощин и балок. Большинство дубрав - нагорные, порослевого происхождения, приурочены к волнистому рельефу (Клявлинский, Исаклинский, Похвистневский районы).

Дубу необходимы свежие почвы и достаточное количество питательных веществ. Лучше всего он растёт на чернозёмах, богатых и свежих суглинках, супесях, но мирится с мелкими каменистыми почвами и выносит засолённость. На бедных песчаных почвах стволы обычно низкие и корявые [3, с. 202]. Такие деревья можно встретить в лесных сообществах Сокольих гор, Красно-Самарском лесничестве, Жигулёвских горах [4, с. 119].

Строительство Саратовского водохранилища в середине 1950-х годов и интенсивный рост городов, окаймляющих лесные массивы левобережья, оказало сильное антропогенное воздействие на жизнеспособность дубрав. В лесостепной части они сменились на порослевые с более низкой производительностью в результате интенсивных рубок 1930-1940 гг. В 1960-х годах в период «рекреационного бума» возросло количество учреждений стационарного отдыха. В основном, они сосредоточены на территории Пригородного и Самарского лесничеств. Увеличение объёма сухостойного леса в 2 раза в пойме р. Волги значительно ухудшило общее санитарное состояние и изменило рекреационный потенциал лесных территорий.

Пригородные дубравы г.о. Самары, в которых основной лесообразующей породой так же является дуб черешчатый, антропогенное воздействие ярко выражено (увеличение площади дачных участков, несанкционированная застройка территории, вырубка деревьев, значительная рекреационная нагрузка и т.д.) и оказывает влияние на растительный покров указанных лесных сообществ, приводя к изменениям не только древостоя, но и всех остальных компонентов фитоценозов. В первую очередь, это касается травянистого яруса $[5$, с. $10-12 ; 6$, с. $269 ; 7$, с. $157 ; 8$, с. 275 ;
Экоморфный анализ флоры пригородных лесов г. Самары

9 , c. $232-235 ; 10$, c. $61 ; 11$, c. $112 ; 12$, c. $17 ; 13$, c. $11-$ 13]. В связи с вышесказанным, объектом исследования были выбраны именно данные территории и актуальным представляется изучить для них состав травостоя и провести экоморфный анализ флоры, что позволит выяснить степень нарушенности данных лесов.

\section{Объекты и методы исследования}

Дубравы Пригородного и Самарского лесничеств. исследовались в летний период 2017-2018 гг. Растительный покров на каждой пробной площади изучался путём обычных геоботанических описаний. Выявлялся флористический состав, обилие проективное покрытие видов растений, жизненное состояние древесных пород, их высота и диаметр. Учитывался рельеф, тип почвы. Проводился анализ флоры [14-19]. Латинские названия растений уточнялись по Т.И. Плаксиной [20; 21]. На основе собранного материала мы попытались провести экоморфный анализ травянистой растительности района исследования, для чего устанавливали принадлежность видов растений к той или иной жизненной форме (биоморфе). Полученные данные позволят определить степень нарушенности растительного покрова под влиянием антропогенного воздействия. Мы использовали систему Л.Л. Бельгарда и работы Н.М. Матвеева [22]. В цели исследования так же входило выяснение структуры древесных растений по категориям состояния, с использованием шкалы Алексеева [23, с. 54-56].

\section{Результаты исследования и обсуждение}

Во флористическом составе исследованных лесов было выявлено 133 вида сосудистых растений из 34 семейств. Все они относятся к отделу Покрытосеменных. Наибольшее распространение получили виды из семейств Бобовые - 13\%, Розоцветные 11,5\%, Сложноцветные - 9,2\%.

Экологические условия оказывают влияние на состав флоры, поэтому было проведено изучение соотношение видов по экоморфам с использованием системы А.Л. Бельгарда (табл. 1-4).

Анализируя ценоморфный состав, можем отметить, что больше всего нами встречено сильвантов от 28 до 78,8\%. Повсеместно встречаются пратанты, степанты, рудеранты. Наличие рудерантов (Stellaria media (L.) Will., Vaccaria hispanica (Mill.) Rauschert., Amaranthus retroflexus L., Chenopodium album L., Polygonum aviculare L., Viola arvensis Murr., Barbarea vulgaris R. Br., Berteroa incana (L.) DC., Capsella bursa-pastoris (L.) Medic., Cardaria draba (L.) Desv., Sisymbrium loeselii L., Agrimonia eupatoria L., Falcaria vulgaris Bernh., Solanum nigrum L., Plantago major L.) является показателем нарушенности сообществ рекреационным воздействием.

таблица 1 - Распределение растений по ценоморфам

\begin{tabular}{|c|l|c|c|c|c|c|c|c|}
\hline \multirow{2}{*}{ № } & \multirow{2}{*}{ Ассоциации } & \multicolumn{5}{|c|}{ Ценоморфа (доля от общего числа видов, \%) } \\
\cline { 3 - 9 } & & Sil & Pr & St & Ru & SilRu & PrRu & StRu \\
\hline 1 & Дубрава бересклетово-разнотравная & 28 & 17 & 10 & 6 & 11 & 4 & 3 \\
\hline 2 & Дубрава лещиново-снытево-подмаренниковая & 66,7 & 7,8 & 3,9 & 3,9 & 13,7 & 2 & 2 \\
\hline 3 & Дубрава лещиново-снытево-волосистоосоковая & 77 & 2,55 & 2,55 & 2,55 & 15,4 & - & - \\
\hline 4 & Дубрава лещиново-снытево-ландышевая & 51,7 & 13,3 & 6,7 & 6,7 & 18,4 & 1,6 & 1,6 \\
\hline 5 & Дубрава бересклетово-ландышево-подмаренниковая & 60 & 10 & 5 & 2,5 & 15 & 5 & 2,5 \\
\hline 6 & Липняк лещиново-ландышево-подмаренниковый & 92 & - & - & - & 8 & - & - \\
\hline 7 & Липняк бересклетово-ландышевый & 78,8 & 3 & 3 & 3 & 12,2 & - & - \\
\hline 8 & Липняк лещиново-снытево-подмаренниковый & 73,5 & 5,9 & - & - & 17,6 & 3 & - \\
\hline
\end{tabular}

Примечание. Sil - сильвант; Pr - пратант; St - степант; Ru - рудерант; SilRu - сильвант-рудерант; PrRu пратант-рудерант; StRu - степант-рудерант. 
Матвеева Т.Б., Казанцев И.В., Молчатский С.Л.

Экоморфный анализ флоры пригородных лесов г. Самары

03.02 .00 - общая биология

Таблица 2 - Распределение растений по гигроморфам

\begin{tabular}{|c|l|c|c|c|c|c|c|c|}
\hline \multirow{2}{*}{ № Ассоциации } & \multicolumn{5}{c|}{ Гигроморфа (доля от общего числа видов, \%) } \\
\cline { 3 - 9 } & & Ms & Ks & KsMs & MsKs & MsHgr & HgrMs & Hgr \\
\hline 1 & Дубрава бересклетово-разнотравная & 35,5 & 11,4 & 30,4 & 1,4 & 6,3 & 2,5 & 2,5 \\
\hline 2 & Дубрава лещиново-снытево-подмаренниковая & 41,2 & 5,9 & 31,4 & 3,9 & 9,8 & 3,9 & 3,9 \\
\hline 3 & Дубрава лещиново-снытево-волосистоосоковая & 48,7 & - & 25,6 & 5,1 & 10,3 & 7,7 & 2,55 \\
\hline 4 & Дубрава лещиново-снытево-ландышевая & 48,3 & 5 & 20 & 6,7 & 10 & 8,3 & 1,7 \\
\hline 5 & Дубрава бересклетово-ландышево-подмаренниковая & 40 & 5 & 32,5 & 7,5 & 5 & 7,5 & 2,5 \\
\hline 6 & Липняк лещиново-ландышево-подмаренниковый & 48 & - & 24 & - & 20 & 4 & 4 \\
\hline 7 & Липняк бересклетово-ландышевый & 51,5 & 3 & 30,3 & - & 9,1 & 6 & - \\
\hline 8 & Липняк лещиново-снытево-подмаренниковый & 53 & - & 26,4 & 2,9 & 11,8 & 5,9 & - \\
\hline
\end{tabular}

Примечание. $M s$ - мезофит; $K s$ - ксерофит; $K s M s$ - ксеромезофит; $M s K s$ - мезоксерофит; $M s H g r-$ мезогигрофит; $H g r M s$ - гигромезофи; $H g r$ - гигрофит.

Таблица 3 - Распределение растений по трофоморфам

\begin{tabular}{|c|l|c|c|c|c|}
\hline \multirow{2}{*}{ № } & \multicolumn{2}{|c|}{ Ассоциации } & \multicolumn{3}{c|}{ Tрофоморфа (доля от общего числа видов, \%) } \\
\cline { 3 - 6 } & & $\operatorname{MgTr}$ & $\operatorname{MsTr}$ & $\operatorname{Og} \operatorname{Tr}$ & $\mathrm{HMg} \operatorname{Tr}$ \\
\hline 1 & Дубрава бересклетово-разнотравная & 39,3 & 57 & 2,5 & 1,2 \\
\hline 2 & Дубрава лещиново-снытево-подмаренниковая & 35,3 & 62,7 & - & 2 \\
\hline 3 & Дубрава лещиново-снытево-волосистоосоковая & 43,6 & 53,9 & - & 2,55 \\
\hline 4 & Дубрава лещиново-снытево-ландышевая & 48,3 & 50 & 1,7 & - \\
\hline 5 & Дубрава бересклетово-ландышево-подмаренниковая & 32,5 & 65 & - & 2,5 \\
\hline 6 & Липняк лещиново-ландышево-подмаренниковый & 40 & 60 & - & - \\
\hline 7 & Липняк бересклетово-ландышевый & 36,4 & 63,6 & - & - \\
\hline 8 & Липняк лещиново-снытево-подмаренниковый & 35,3 & 64,7 & - & - \\
\hline
\end{tabular}

Примечание. $M g T r$ - мегатроф; $M s T r$ - мезотроф; $O g T r$ - олиготроф; $H M g T r$ - галомегатроф.

Таблица 4 - Распределение растений по жизненным формам (биоморфам), по И.Г. Серебрякову [16; 17]

\begin{tabular}{|c|c|c|c|c|c|c|c|c|c|c|c|c|c|c|c|}
\hline \multirow{2}{*}{ № } & \multirow{2}{*}{ Ассоциации } & \multicolumn{14}{|c|}{ Биоморфа (доля от общего числа видов, \%) } \\
\hline & & Б1 & Б2 & Б3 & Б4 & Б5 & Б6 & Б7 & Б8 & Б9 & Б10 & Б11 & Б12 & Б13 & Б14 \\
\hline 1 & $\begin{array}{l}\text { Дубрава бересклетово- } \\
\text { разнотравная }\end{array}$ & 23 & 21,8 & - & 2,6 & 11,5 & - & 3,8 & 3,8 & 2,6 & 2,6 & 1,3 & 21,8 & 1,3 & 2,6 \\
\hline 2 & $\begin{array}{l}\text { Дубрава лещиново-снытево- } \\
\text { подмаренниковая }\end{array}$ & 16 & 34 & 2 & 10 & 14 & 2 & 2 & 2 & - & - & 2 & 14 & 2 & - \\
\hline 3 & $\begin{array}{l}\text { Дубрава лещиново-снытево- } \\
\text { волосистоосоковая }\end{array}$ & 20,5 & 28,2 & 2,55 & 7,7 & 20,5 & 2,55 & - & 5,1 & 2,55 & 2,55 & - & 5,1 & 2,55 & - \\
\hline 4 & $\begin{array}{l}\text { Дубрава лещиново-снытево- } \\
\text { ландышевая }\end{array}$ & 21,3 & 26,2 & 1,6 & 6,6 & 11,5 & 3,3 & - & 5 & 3,3 & 1,6 & 1,6 & 14,8 & 1,6 & 1,6 \\
\hline 5 & $\begin{array}{l}\text { Дубрава бересклетово-лан- } \\
\text { дышево-подмаренниковая }\end{array}$ & 24,4 & 29,3 & - & 4,9 & 14,7 & - & 2,4 & 2,4 & 2,4 & - & 4,8 & 9,8 & 2,4 & - \\
\hline 6 & $\begin{array}{l}\text { Липняк лещиново-лан- } \\
\text { дышево-подмаренниковый }\end{array}$ & 28 & 32 & 4 & 16 & 16 & - & 4 & - & - & - & - & - & - & - \\
\hline 7 & $\begin{array}{l}\text { Липняк бересклетово- } \\
\text { ландышевый }\end{array}$ & 20,6 & 38,3 & 2,9 & 8,8 & 14,7 & - & - & 3 & - & 2,9 & - & 8,8 & - & - \\
\hline 8 & $\begin{array}{l}\text { Липняк лещиново-снытево- } \\
\text { подмаренниковый }\end{array}$ & 26,5 & 41,2 & - & 8,8 & 8,8 & - & - & 2,9 & 5,9 & - & - & 2,9 & 2,9 & - \\
\hline
\end{tabular}

Примечание. Б1 - длиннокорневищные; 52 - короткокорневищные; Б3 - с ползучим корневищем; Б4 - деревья; Б5 - кустарники; Б6 - полукустарники; 57 - однолетние; 58 - двулетние; 59 - рыхлодерновинные; 510 - клубнеобразующие; 511 - кистеклубневые; $Б 12$ - стержнекорневые; 513 - стержнекистевые; Б14 - корнеотпрысковые.

Изученная флора имеет мезофильный характер, поскольку из гигроморф чаще других встречаются мезофиты (Chelidonium majus L., Viola canina L., Alliaria petiolata (Bieb.) Cavara et Grande., Geum urbanum L., Potentilla argentea L.), что свидетельствует о достаточном количестве почвенной влаги. Примесь ксеромезофитов (Anemone sylvestris L., Delphinium cuneatum Stev. ex DC., Pulsatilla patens (L.) Mill., Ranunculus polyanthemos L., Dianthus deltoides L.) и мезоксерофитов (Consolida regalis S.F. Gray., Silene nutans L., Vaccaria hispanica (Mill.) Rauschert., Amaranthus retroflexus L.) отражает существенные колебания режима почвенного увлажнения. Влаголюбивые гигромезофиты (Asarum europaeum L., Anemonoides ranunculoides (L.) Holub., Corydalis bulbosa (L.) DC., Urtica dioica L.) и мезогигрофиты (Clematis integrifolia L.,
Ranunculus acris L., Thalictrum flavum L., Rumex confertus Willd.) представлены меньшим числом видов.

Трофоморфный состав ассоциаций показывает, что подавляющее большинство растений относится к мезо- (Aristolochia clematitis L., Adonis vernalis L., Lathyrus pratensis L., Securigera varia (L.) Lassen., Geranium sanguineum L., Salvia pratensis L., Taraxacum officinale Wigg. s.l., Elytrigia repens (L.) Nevski.) и мегатрофам (Aquilegia vulgaris L., Lysimachia nummularia L., Amoria montana (L.) Sojak., Chaerophyllum bulbosum L., Achillea millefolium L., Millium effusum L.). Это объясняется почвенным богатством.

При оценке биоморфного состава следует отметить, что древесные растения составляют $8,5 \%$ от видового разнообразия. Основной лесообразующей породой является Quercus robur L., Acer platanoides 
Матвеева Т.Б., Казанцев И.В., Молчатский С.Л.

03.02.00 - общая биология

L., Tilia cordata Mill., Ulmus laevis Pall. В кустарниковом ярусе $(9,2 \%)$ доминирующее положение занимают Corylus avellana L. и Euonymus verrucosa Scop. В травянистом ярусе наибольший процент занимают длинно- (Saponaria officinalis L., Stellaria graminea L., Chamerion angustifolium (L.) Holub., Veronica chamaedrys L., Poa pratensis L.) и короткокорневищные (Thalictrum simplex L., Hypericum perforatum L., Fragaria viridis (Duch.) Weston., Galium boreale L., Ajuga
Экоморфный анализ флоры пригородных лесов г. Самары genevensis L., Artemisia vulgaris L.) растения. Они встречаются во всех выделенных ассоциациях. Менее всего встречаются корнеотпрысковые (Cirsium arvense (L.) Scop., Convolvulus arvensis L.), они отмечены лишь в двух ассоциациях.

В результате исследований мы установили, что в древостоях Quercus robur L. характеризуется ослабленным состоянием и данные лесные массивы мы не можем отнести к здоровым (табл. 5).

таблица 5 - Характеристика жизненного состояния лесообразующих пород в ассоциациях

\begin{tabular}{|c|l|c|c|c|c|}
\hline \multirow{2}{*}{ № } & \multicolumn{2}{|c|}{ Ассоциации } & \multicolumn{3}{c|}{ Жизненное состояние, \% } \\
\cline { 3 - 6 } & & $\begin{array}{c}\text { Quercus } \\
\text { robur L. }\end{array}$ & $\begin{array}{c}\text { Acer } \\
\text { platanoides L. }\end{array}$ & $\begin{array}{c}\text { Tilia } \\
\text { cordata } \text { Mill }\end{array}$ & $\begin{array}{c}\text { Ulmus } \\
\text { laevis } \text { Pall. }\end{array}$ \\
\hline 1 & Дубрава бересклетово-разнотравная & $61-\Pi$ & - & - & - \\
\hline 2 & Дубрава лещиново-снытево-подмаренниковая & $67,8-\Pi$ & $91,6-3$ & $95-3$ & $91,7-3$ \\
\hline 3 & Дубрава лещиново-снытево-волосистоосоковая & $85-3$ & $99-3$ & $86,7-3$ & - \\
\hline 4 & Дубрава лещиново-снытево-ландышевая & $62-\Pi$ & $92-3$ & $88-3$ & - \\
\hline 5 & Дубрава бересклетово-ландышево-подмаренниковая & $60-\Pi$ & $90-3$ & - & - \\
\hline 6 & Липняк лещиново-ландышево-подмаренниковый & $61,2-\Pi$ & $88,7-3$ & $81,5-3$ & - \\
\hline 7 & Липняк бересклетово-ландышевый & $29,7-$ сп & $95,5-3$ & $94,4-3$ & - \\
\hline 8 & Липняк лещиново-снытево-подмаренниковый & $61-\Pi$ & $90,4-3$ & $88,7-3$ & $90-3$ \\
\hline
\end{tabular}

Примечание. Жизненное состояние: з - здоровое; $n$ - повреждённое; $c n$ - сильно повреждённое.

Хорошее жизненное состояние отмечено лишь в одном квартале Мехзаводского лесопаркового участка (6/16), что, по-видимому, связано с возрастом деревьев (150 лет). Сильнее всего усыхают деревья (сильно ослабленное состояние) на территории 93 квартала 9 выдела (Сокольи горы), что может быть связано с выходом карбонатов.

В целом, по шкале категорий «Санитарные правила в лесах РФ» [24], состояние насаждений с учётом сухостоя на данных участках оценено как хорошее. В большинстве лесных кварталов сухостой отсутствует. Увеличение сухостоя, по данным лесоустройства последних лет, наблюдается в лесных кварталах Пригородного лесничества, представленных отдельными лесными массивами, разрезанными магистральными дорогами, селитебной застройкой, садово-дачными и сельскохозяйственными участками.

Установлено, что в большей мере на степень усыхания оказывает влияние не столько характер почв, в пределах типа, сколько гранулометрический состав и глубина вскипания карбонатов. Нами отмечено, что с уменьшением глубины залегания карбонатов, жизненное состояние ухудшается. Лучшее жизненное состояние отмечено в дубраве лещиновоснытево-волосистоосоковой с глубиной вскипания $130 \mathrm{~cm}-85,6-88 \%$. В сообществах, где вскипание карбонатов с поверхности - жизненное состояние колеблется от $29,7-76,2 \%$.

\section{Заключение}

Таким образом, травостой разнообразен по видовому составу и включает 133 вида сосудистых растений, среди них наличие рудерантов свидетельствует о нарушенности растительного покрова. В древостое доминируют Quercus robur L., Acer platanoides L., Tilia cordata Mill., Ulmus laevis Pall., жизненное coстояние которых оценивается, в основном, как повреждённое. Большую ценность представляют древостои дуба в возрасте 100-150 и более лет (6 квартал).

Полученные материалы могут служить основой для дальнейшего мониторинга пригородных лесов зелёной зоны г. Самары.

\section{Список литературы:}

1. Шаров В.М. Ландшафты и лесопарковые участки у г. Куйбышева // Лесное хозяйство Куйбышевской области. Куйбышев: Кн. изд-во, 1976. С. 150-157.

2. Шабалин И.М. Самарский лес. Самара: Изд-во «Самара», 2005. 76 c.
3. Пустовалова Л.А., Ерохина О.В., Никонова Н.Н. Современное состояние лесов с участием Quercus robur L. на северо-восточном пределе его распространения // Отечественная геоботаника: основные вехи и перспективы: мат-лы всерос. конф. Т. 1. СПб., 2011. C. 201-203.

4. Лобанов Я.Я. Дуб - главная порода в лесоразведении // Лесное хозяйство Куйбышевской области. Куйбышев: Кн. изд-во, 1976. С. 117-129.

5. Березуцкий М.А. Антропогенная трансформация флоры // Ботанический журнал. 1999. Т. 84, № 6. C. 8-20.

6. Болдырев В.А. Влияние рекреации на состав и структуру нагорных лесов Саратовского Правобережья // Охрана, обогащение и использование растительных ресурсов: тез. докл. всесоюз. науч. совещания (к 30-летию Ставропольского ботанического сада. Ставрополь: Ставропольское краевое управление статистики, 1990. С. 268-269.

7. Болдырев В.А. Влияние рекреационного вытаптывания на некоторые лесные фитоценозы в Саратовском Правобережье // Вопросы экологии и охраны природы в лесостепной и степной зонах: межвуз. сб. науч. тр. Вып. 1 / под ред. Н.М. Матвеева. Самара: Изд-во «Самарский университет», 1995. С. 155-160.

8. Григорьевская А.Я. Анализ флоры дубрав городского округа г. Воронеж // Современные проблемы морфологии и репродуктивной биологии семенных растений: мат-лы междунар. конф., посв. памяти Р.Е. Левиной / отв. ред. С.Н. Опарина. Ульяновск: Ульяновский государственный педагогический ун-т им. И.Н. Ульянова, 2008. С. 269-277.

9. Карманова И.В., Рысина Г.П. Поведение некоторых лесных видов растений в нарушенных лесных сообществах // Изв. АН РАН. Серия биол. 1995. № 2. C. 231-239.

10. Михайлова И.Н., Вардания Е.В. Оценка антропогенного воздействия на дубравы г. Чебоксары методом дорожно-тропиночной сети // Изучение растительных ресурсов Волжско-Камского края: мат-лы всерос. науч.-практ. конф. 3-5 октября 2008 г., г. Чебоксары, Российская Федерация / гл. ред. В.Г. Папченков. Чебоксары, 2008. С. 60-62.

11. Рысин Л.П., Савельева Л.И., Полякова Г.А., Рысин С.Л., Беднова О.В., Маслов А.А. Мониторинг рекреационных лесов. М.: ОНТИ ПНЦ РАН, 2003. 168 с. 
12. Невский С.А. Антропогенная динамика нагорных лесов Саратовского Правобережья: автореф. дис. ... канд. биол. наук. Тольятти, 2001. 23 с.

13. Рассказова М.М. Оценка состояния некоторых лесных фитоценозов в условиях рекреационной нагрузки: автореф. дис. ... канд. биол. наук. Калуга, $2006.31 \mathrm{c}$.

14. Благовещенский В.В. Определитель растений Среднего Поволжья. Л.: Наука, 1984. 392 с.

15. Маевский П.Ф.Флора средней полосы европейской части СССР. Л.: Колос, 1964. 880 с.

16. Серебряков И.Г. Экологическая морфология растений: Жизненные формы покрытосеменных и хвойных. М.: Изд-во «Высшая школа», 1962. 378 с.

17. Серебряков И.Г. Жизненные формы высших растений и их изучение. Полевая геоботаника. Т. 3. М.-Л.: Изд-во «Наука», 1964. С. 146-205.

18. Сосудистые растения Самарской области: учеб. пособие / под ред. А.А. Устиновой, Н.С. Ильиной. Самара: Изд-во «Содружество», 2007. 400 с.
19. Черепанов С.К. Сосудистые растения России и сопредельных государств (в пределах бывшего СССР). СПб.: Мир и семья, 1995. 992 с.

20. Плаксина Т.И. Конспект флоры Волго-Уральского региона. Самара: Изд-во «Самарский университет», 2001. $388 \mathrm{c.}$

21. Плаксина Т.И. Анализ флоры: учеб. пособие. Самара: Самарский университет, 2004. 152 с.

22. Матвеев Н.М. Биоэкологический анализ флоры и растительности (на примере лесостепной и степной зоны): учебное пособие. Самара: Изд-во «Самарский университет», 2006. 311 с.

23. Алексеев В.А.Диагностика жизненного состояния деревьев и древостоев // Лесоведение. 1989. № 4. C. 51-57.

24. Санитарные правила в лесах Российской Федерации (утв. Приказом Рослесхоза от 18.05.1992 № 90) (ред. от 20.01.1995) (Зарегистрировано в Минюсте РФ 14.09.1992 № 58).

\title{
ECOMORFS ANALYSIS OF THE SAMARA FLORA
}

(C) 2019

Matveeva Tatyana Borisovna, candidate of biological sciences, associate professor of Biology, Ecology and Methods of Teaching Department

Kazantsev Ivan Victorovich, candidate of biological sciences, associate professor of Chemistry, Geography and Methods of Teaching Department, dean of Faculty of Natural Sciences and Geography Molchatsky Sergey Lvovich, candidate of physical and mathematical sciences, associate professor of Chair of Chemistry, Geography and Methods of Teaching Samara State University of Social Sciences and Education (Samara, Russian Federation)

Abstract. During the conducted research it is revealed that suburban forests of Samara experience a considerable anthropogenic load. It is connected with the increase of the country site area, unauthorized building of the territory, deforestation, recreational loading. For the allocated associations the analysis of ecomorphs of flora is carried out. All species on coenomorphes, hygromorphes and trophomorphes are distributed. On the basis of the obtained data primary distribution of elements of flora was established. The main consequences of anthropogenic transformation are also revealed. It is possible to conclude that the structure of herbage of Samara suburban forests changes in the process of anthropogenic loading increase. It is reflected in ruderants, xeromesophytes and mesoxerophytes increase. It is not peculiar for forest communities. On the basis of the obtained data it is possible to define a disturbance degree of a vegetable cover under the anthropogenic influence. It is revealed that in suburban forests of Samara, despite high appeal and comfort, the vital condition of forest stands of an oak is weakened. It is necessary to carry out a complex of forestry and landscape actions for optimization of recreational forest exploitation that will improve a condition of forest plants and increase their stability in the conditions of anthropogenic loading. These materials can form a basis for a further study of the flora of the area.

Keywords: anthropogenic influence; recreational pressure; suburban forests; associations; forest stands; oak forest; lime-forest; ecomorphs analysis of flora; vascular plants; coenomorpha; hygromorpha; trofomorpha; vital forms; vital state; dead wood; forest forming breed; Quercus robur L.; monitoring.

\section{ПИТАНИЕ СЕМИТОЧЕЧНОЙ КОРОВКИ СОССINELLA SEPTEMPUNCTATA L. (COLEOPTERA, COCCINELLIDAE) НА РАЗЛИЧНЫХ СТАДИЯХ ЖИЗНЕННОГО ЦИКЛА} (C) 2019

\author{
Минияров Фарит Талгатович, кандидат биологических наук, доцент кафедры \\ биотехнологии, зоологии и аквакультуры, заведующий лабораторией экспериментальной зоологии \\ Астраханский государственный университет (2. Астрахань, Российская Федерация) \\ Павлов Сергей Иванович, кандидат биологических наук, \\ доцент кафедры биологии, экологии и методики обучения
}

Яицкий Андрей Степанович, старший преподаватель кафедры биологии, экологии и методики обучения Самарский государственный социально-педагогический университет (2. Самара, Российская Федерация)

Аннотация. В работе представлены результаты исследований по изучению жизненного цикла семиточечной коровки (Coccinella septempunctata L.) с двумя ежегодными поколениями в климатической зоне юга России. Основные этапы жизненного цикла: выход имаго с зимней диапаузы, первое поколение от яйца до има- 